film progresses, she becomes involved with his patients and the complexities of their medical conditions and their lives. Near the film's conclusion, she has to decide whether she is prepared to take on Rainville's practice permanently.

Dion's twin journeys don't offer simplistic resolutions to her professional quandaries, nor do they romanticize rural medical practices over urban

ones. What these understated, meditative films do register is a sense of medicine as a vocation with spiritual connotations, as if the mystery of the human soul must be seen to be part of how medicine is practised in a world of advanced scientific technologies and treatments. Rainville states matter-offactly that he is "here to serve." His humility appears genuine, tough-

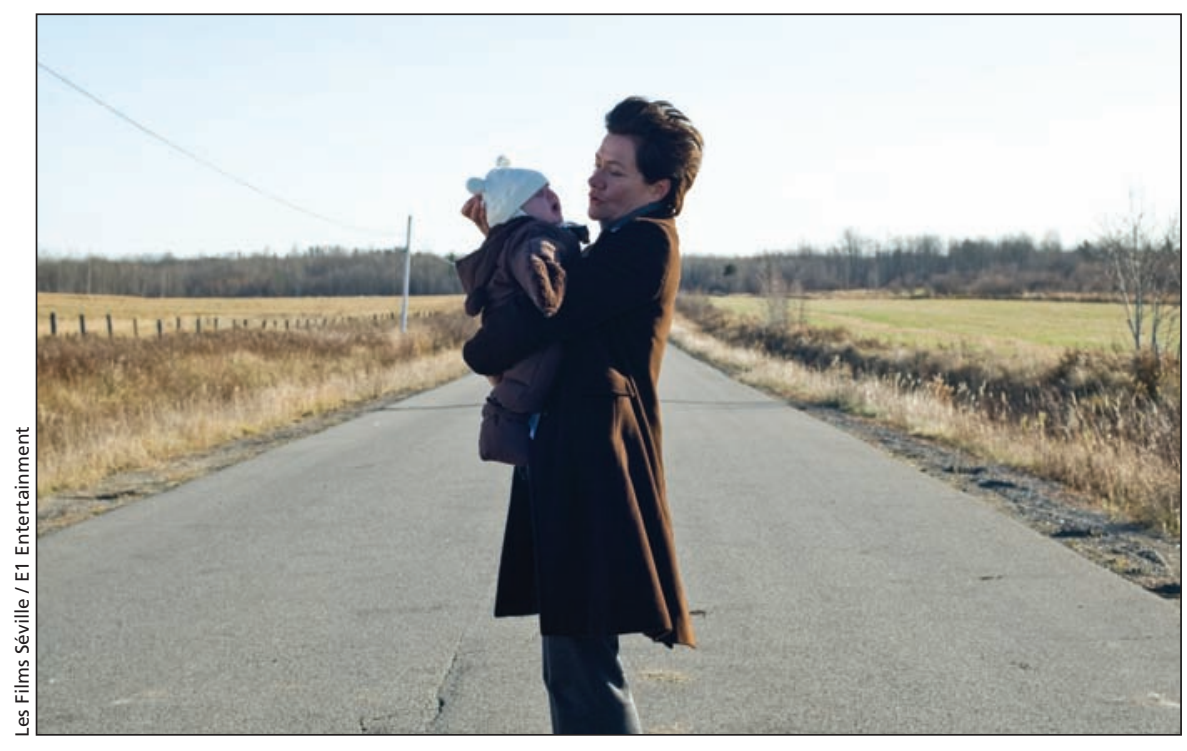

Dion takes on a small-town practice in the Abitibi region of Quebec and discovers the way back toward a more compassionate approach to medicine. minded and practical for a physician, and it inspires Dion with the quiet force of its example.

Émond's depiction of Dion's crises, her sense of her limitations as a doctor and her shaken but not destroyed commitment to compassion, is as sobering as it is hopeful.

The films intelligently raise important moral, ethical and philosophical questions about the role of the physician in society. These are the same questions raised by Hippocrates, questions that are both essential and, in a paradoxical sense, unanswerable. What is essential is not their being answered but rather the raising and reframing of these questions, as medical science evolves, in contemporary social contexts and changing medical practices. Films like The Novena and The Legacy contribute to that process in both useful and aesthetically impressive ways.

\section{Tom McSorley}

Executive director

Canadian Film Institute

Ottawa, Ont.

Tom McSorley is a sessional lecturer in the Department of Film Studies at Carleton University, Ottawa, Ont. and film critic for CBC Radio One's, Ottawa Morning.

\title{
Wanted: Historical artifacts for new public health school
}

$\mathrm{W}$

hy decorate walls with accent colours and bad art when you can use the space to educate the public and students? That's the thinking behind the proposed public health museum (both actual and virtual) at the School of Population and Public Health's newly renovated building at the University of British Columbia, Vancouver, BC.

"We already have some remarkable - objects," says Dr. Erica Frank, a professor at the school and the museum's organizer. These include an iron lung, quarantine signs, an old British Columbia Centre for Disease Control public health laboratory, immunization paraphernalia, the Nobel Peace prize certifi- cate awarded to the International Physicians for Prevention of Nuclear War and art about mental illness. The building is slated to open in summer 2010.

Frank is looking to borrow other public health related artifacts (erica.frank @ubc.ca).

Many of the objects will be accompanied by a narrative and photograph of a person who benefited from the object. For example, a woman whose father was in an iron lung for two years will write about how that experience allowed her to exist.

Another twist is that this summer's intern will be Frank's 12-year-old son, Ridge Frank-White, who will be making a photographic record of all the objects to put on a website. "I know, it's an age-inappropriate activity," quips Frank. "But some parents like to play soccer or hockey with their kids; I like to work with mine." Frank-White has attended all the planning meetings and helped to situate the exhibit spaces.

"It's going to be great," says Frank. "It sure beats hanging trite motivational posters on the wall."

\section{Barbara Sibbald BJ}

Deputy editor, analysis and humanities CMAJ

Erica Frank is a member of the CMAJ editorial board. 